\title{
Identifying appropriate options for delivering urban transportation to older people
}

\author{
J. F. Brake \\ School of Civil Engineering and Geosciences, Newcastle University, UK
}

\begin{abstract}
The range of possible options to deliver public transport services to older people in urban areas is discussed in the context of the ageing population structure in the UK. These services include registered conventional fixed route bus services, semi-fixed and flexible services, non-registered services specifically supported by local authorities and community transport operators, together with taxi and car club and car share options. Some of these services have restricted end user segments. Each service type contributes to catering for the needs of older people, as demonstrated by the case studies of a shopping service for older people targeted at residents of sheltered housing and the improvement in the delivery of services for more immobile older people. The case studies show that consultation with stakeholders can improve the appropriateness and success of the services offered. The development of a package of services (including support for passengers) that under pin the core conventional fixed route services demonstrates how older peoples' needs can be addressed. Strong emphasis is placed upon the importance of consultation with and dissemination to stakeholders in order to deliver services.

Keywords: public transport, community transport, old people, social inclusion, social exclusion, barriers, mobility, accessibility, stakeholder consultation, dissemination.
\end{abstract}

\section{Introduction}

Increasingly it is recognised that the successful delivery of public transport services requires careful consideration of the different market segments. Using case studies this paper considers how to provide the various options now available to deliver transportation for older people living in urban areas. 
This paper is structured as follows: first the context of the paper is provided by outlining the importance of urban public transport for older people; this is followed by a description of urban public transport options and how they can be applicable to older people. Case studies identify appropriate travel options as part of a package of services and show the importance of dissemination.

\section{The importance of urban public transport for older people}

The profiles of European populations are increasingly showing an ageing structure, the UK being no exception (Figure 1 [1]). The total population increased by $8 \%$ from 55.9 million in 1971 to 60.6 million in mid-2006 whereas the population aged over 65 grew by $31 \%$, from 7.4 to 9.7 million. Whilst the overall health of this ageing population is improving and the onset of severe mobility problems are being delayed, the size of the older population will continue to increase and their specific transport needs must be met. Many older people are amongst the most socially excluded members of society and transport related social exclusion is a key contributory factor to this exclusion [2].

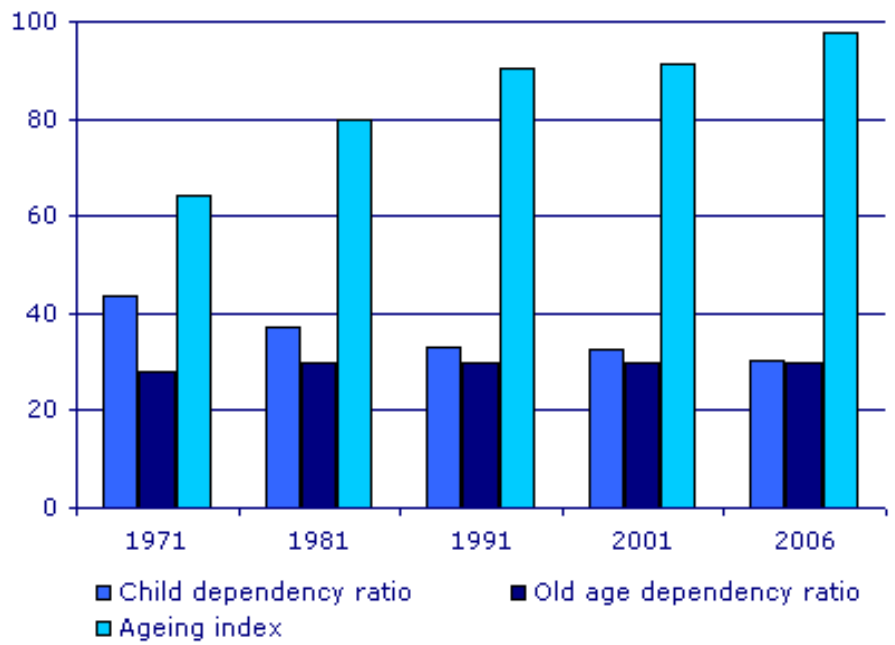

Source: http://www.statistics.gov.uk (2008)

Figure 1: UK age structure indicators.

Social exclusion is common to both urban and rural areas, but some aspects are more acute in urban areas. Family networks of support for older people have become weaker as employment mobility increases, leading to infrequent contact. This is exacerbated by the increasing number of homes with only one household member, due to the higher rates of marital/family breakdown. Thus, many older people have neither children nor a spouse/partner to support their mobility requirements. In urban areas the ethos of looking after elderly neighbours is being eroded rapidly by factors such as longer working hours, formal use of 
leisure time and, once again, people moving house more often so that caring relationships between neighbours do not develop.

The current generation of older people has enjoyed high car ownership, producing many people who are not familiar with accessing public transport services, particularly the bus network. The subsequent decreasing demand has also contributed to the decline in the urban public transport network.

This situation was exacerbated by the deregulation of local bus services in 1986 (Transport Act 1985) so that commercial operators select the most profitable routes, leaving local authorities to support routes that enhance accessibility to public transport services where it is considered to be most needed. However, local authority transport budgets are not finite and support has to be spread amongst competing demands, such as access to jobs and training, as well access to destinations required by older people. In 2006 the UK Transport Select Committee reported that the current system of competition is "clearly failing many non-core routes and the communities [that] depend on them." [3]. It noted that although bus passenger numbers have been falling since the $1950 \mathrm{~s}$, deregulation has done little to halt this - between 2000 and 2005, they fell by $7 \%$ in the regions outside London, whereas in London, which remains regulated, there has been a $32 \%$ increase. Overall deregulation has led to a concentration of routes on profitable corridors and fragmentation of the network, making it particularly difficult for older people to travel on local public transport.

An additional contributor to age related social exclusion has been the radical change in the network for providing goods and services: larger supermarkets and out of town shopping centres are ideally suited for access by car owners - but not by public transport. The consequent decline in local and district shopping centres has left many people isolated from the essential services that they need. Access to non-essential destinations is frequently even more difficult.

\section{Urban public transport options for older people}

This section outlines the range of possible public transport options for older people in the UK; options are categorised according to descriptors which have a particular impact on older people, e.g. whether the service is available to older people, the fares, route flexibility and whether it is pre-booked [4]. Figure 2 outlines these options. A broad definition of public transport is any transport service excluding the use of the private car within a household: this allows the inclusion of non-conventional methods by which the population can travel.

Public transport services available to the general public (in theory if not in practice) have to be registered with the Traffic Commissioners. Under the Transport Act 1985 registration requires the applicant to describe the route and the operating schedule. Such services are provided under a standard (Section 21) or restricted (Section 13) Public Service Vehicle (PSV) operator's permit provided by a profit making body (i.e. a commercial operator), but it can also include a non-profit making body (such as a community transport operator) providing a registered service (Section 22) [5]. People aged over 65 years are entitled to free off-peak concessionary travel on these services. 


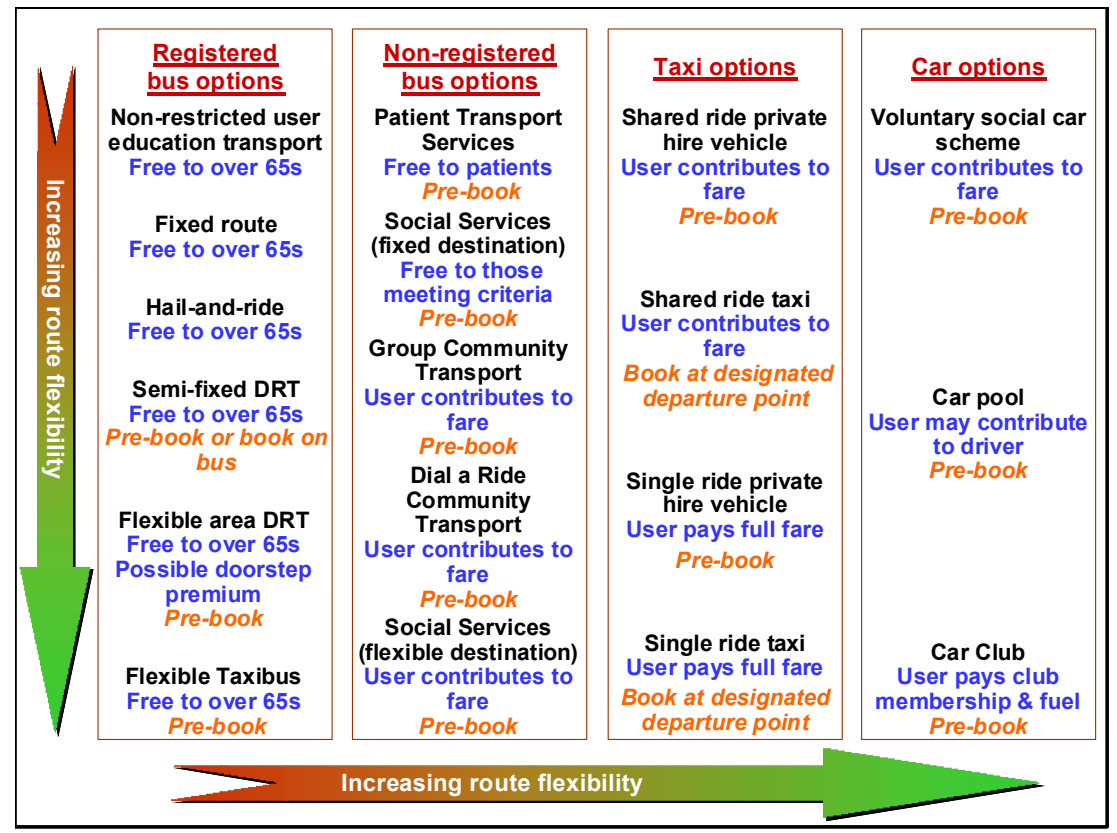

Figure 2: $\quad$ Urban public transport options for older people.

Public transport services available to the general public have to be registered with the Traffic Commissioners. The Transport Act 1985 requires the applicant to describe the route and the operating schedule. Such services are provided under a standard (Section 21) or restricted (Section 13) Public Service Vehicle (PSV) operator's permit by a profit making body (a commercial operator), but it can also include a non-profit making body (e.g. a community transport operator) providing a registered service (Section 22) [5]. People aged over 65 years are entitled to free off-peak concessionary travel on these services.

The conventional registered bus service is a fixed route calling at designated bus stops at fixed times. Hail-and-ride services can operate on all or part of a registered fixed route service: the user waits at a safe location on the fixed route and indicates to the driver that he wishes to be picked up. Semi-fixed Demand Responsive Transport (DRT) services are even less conventional as some or the entire route is flexible. For one variant, at flexible sections the vehicle returns to the fixed route at the point of departure from it. Requests to deviate may be made to the driver on the bus or by pre-booking via a Call Centre or the operator. Another variant has an entirely semi-fixed route: upon request, the vehicle deviates from the shortest route between designated fixed stopping points in order to pick up/drop off and it may not return to the point it departed from the shortest route. Fully flexible DRT services also have characteristic service designs. The most common design is to fix the start and end times. Once the service journey has started the route is, in theory, fully flexible. The service journey ends at (or before) a fixed time at a specific destination. Less common 
is the "virtual" flexible route in which there are no fixed starting or end points: the vehicle roams the service area for the duration of the service. Bookings for the second semi-fixed service type and fully flexible services are made prior to travel via a Call Centre, the operator or the internet. With a special PSV licence taxi operators can also register flexible taxibus services (Section 12) that are usually booked with the taxi operator. Non-conventional services offer considerable benefits to older people: the more flexible the service, the closer the passenger can be to the doorstep at the beginning and end of the journey. There may be a premium fare for doorstep pick-ups/drop-offs.

Outside London commercial operators provide registered services where they derive an acceptable profit: the cost of establishing and operating semi-fixed and especially flexible transport services (often beneficial to older people) is usually regarded as unacceptable to commercial operators. In contrast, local authorities support transport services that meet the objectives of that local authority. In large metropolitan areas a Passenger Transport Executive (PTE) has a budget to meet the objectives of the Passenger Transport Authority (PTA) for that area. These objectives (such as social inclusion) are embodied in the Local Transport Plan (LTP) by the PTA and the constituent metropolitan boroughs. (The PTA is composed of elected councillors from these boroughs.) Each non-metropolitan local authority is responsible for its own LTP. Registered services supported by the local authority/PTE are tendered for by commercial and community transport operators. From $1^{\text {st }}$ April 2008 local authorities/PTEs must subsidise free concessionary fares for all over 65 year olds, regardless of whether the person is travelling in the local authority where he/she lives. In recognition of the local transport budget being diverted from supporting the provision of the actual transport services, additional funding of $£ 212 \mathrm{~m}$ will be provided by a special Government grant for 2008/9, with $£ 217 \mathrm{~m}$ in $2009 / 10$ and $£ 223 \mathrm{~m}$ in $2010 / 11$ [6].

The LTP not only permits the support of registered services, but also nonregistered services that are targeted to the needs of segments of the population, e.g. schools and social services transport. Schools transport is not applicable to older people unless a service is registered for use by the general public. Such services are seldom useful to older people as they have inappropriate destinations and operate at inappropriate times of day, e.g. the concessionary fare is not available during the morning peak when school services operate; older people are likely to want to return home long before the afternoon return trip. The services are contracted for by commercial and community transport operators.

Social services transport is available to older people with particular mobility constraints - they are not for more able-bodied older people. Trips are often made to targeted destinations such as lunch clubs and centres offering day care. The fares structure varies between authorities, often being free to the user. PTEs also offer social transport services that can be booked by an individual to a destination of his/her own choice within the local authority at a nominal fare. The criteria for carriage on these services are strictly defined, (varying between PTEs). The services are operated by the local authority/PTE or contracted out to community transport, taxi operators and small commercial operators. 
Some local authorities support voluntary social car schemes: they are booked by people who have no other means of transport for essential journeys. The volunteer driver (using his/her own vehicle) has a mileage allowance that is jointly paid for by the passenger and the local authority. These services are eminently suitable for older people, but are more often provided in rural areas.

As with registered semi-fixed and flexible transport services, bookable social transport services require a scheduling mechanism: given the reluctance of commercial operators to establishing flexible transport services, local authorities are an appropriate entities to fund an in house or contracted out Call Centre.

Community transport operators make a significant contribution to the transport of older people, not only through registered services and contracts for local authority social transport services but also non-registered services that are not for the general public (Section 19, Transport Act 1985). They are identified by the community transport operator in response to the gaps in the public transport network. The most common applications are group transport (in which the operator or a hiring group provide a driver) and dial-a-ride (an individual books a door-to-door trip on a flexible route). Concessionary fares for older people are not accepted on Section 19 services. Dial-a-ride was the predecessor of registered flexible transport services: it has been provided by community transport for over 30 years - these organisations are well placed to provide all forms of flexible transport services, including the hosting of a Call Centre.

Taxis and private hire cars licensed under Taxi and PHV Service Licensing (Section 12, Transport Act 1985) enable individual flexible door-to-door transport at a higher fare than registered and non-registered bus services. Section 11 permits pre-booked shared taxi rides that start or end at a common origin or destination, whilst Section 10 allows shared rides to be arranged at designated taxi ranks and other designated locations [7]. For both these arrangements the fares for each person is a proportion of the metered fare, making them financially more attractive to older people than single ride taxi trips.

Patient Transport Services are provided by the local Ambulance Service for trips to non emergency medical appointments where the patient does not have access to a car. These free services are often used by older people, but the destinations are limited in terms of location, timing and journey purpose.

Car sharing and car clubs have emerged in the private sector. Anyone can join a car share scheme as a potential lift giver and/or taker: participants specify their origin, destination and travel times and make further restrictions based on gender and whether they will travel with someone who smokes. The most common mechanism for seeking trip matches is through lift/car sharing websites. Money may be exchanged between the passenger and driver. Thus, provided they can match trips car sharing is suitable for older people: whilst most car sharing occur in urban areas, they are most frequent with commuting trips.

Members of car clubs are given key coded access to the fleet of cars which are placed at strategic locations. Due to logistical constraints, car clubs are almost always located in urban areas. There is a membership fee as well as a charge for fuel used. Car clubs have considerable potential for older people who give up their own car for financial reasons or due to infrequent use. 


\section{Appropriate transport options}

The previous section identified potential public transport options for older people who do not have personal access to a private car. This section goes on to suggest how older people can gain access to the most appropriate options.

\subsection{Stakeholder requirements}

The delivery of appropriate services by local authorities to targeted segments of the population (such as the elderly) is unlikely to be met by supporting a limited number of options, since each option will have disadvantages and advantages for different users. However, cost constraints make 100\% coverage by all options unrealistic. The solution is to find a package of measures that best meet the requirements of all stakeholders. The key stakeholders are the local authority (both elected councillors and employees who implement the LTP), the operators, the passengers and organisations that represent their interests, and organisations that benefit from passengers being able to travel to them. Accessibility planning toolkits such as Accession [8] and Withinreach [9] help implement the LTP: an essential part of accessibility planning is consultation with stakeholders.

Evaluation of a Community Transport Shopping Pilot in Newcastle [10] and a TaxiLink-TaxiCard Survey [11] are examples of stakeholder consultation on behalf of Nexus (the Tyne and Wear PTE) that illustrate how to overcome mobility barriers for older people. The TaxiLink care service for disabled and elderly people was funded by Nexus. It provided a door-to-door service for people meeting strict mobility criteria but did not achieve passenger expectations, e.g. difficulty contacting the Call Centre and inability to make a successful booking. The survey presented options to replace the service with a TaxiCard scheme that would guarantee a certain number of partly subsidised trips per year (compared with the TaxiLink theoretical offer of an unlimited number of trips that could not be met with the contract). TaxiCard was thought to be acceptable since the booking is directly with the taxi operator, a specified number of trips are guaranteed, repeat bookings can be made, bookings can be made close to the time of travel and trip destinations are less restrictive [11].

The Shopping Pilot evaluation concerned a Section 19 community transport service partly funded by Nexus for people aged over 50 who have difficulty obtaining essential shopping on registered services. A number of routes are each offered fortnightly. The services start at sheltered housing (where there is a strong need for this service) and end at a supermarket, picking up members of the wider community en route. The return journey is 1-2 hours later. The need for this service was identified by Newcastle Age Concern and the Quality of Life Partnership (QLP) following changes to the Newcastle meals-on-wheels service. Focus Groups revealed additional reasons for its popularity: the social aspects of travelling in a group; the simple service design; compared to fixed routes journey times are appropriate, vehicles are comfortable, passenger care is good and a seat is guaranteed; booking through the QLP is easy compared with getting through to a Call Centre and making a booking with LinkUp (a Nexus supported flexible transport service); there is less dependence on other people for lifts; ex-car users 
feel confident with this form of public transport; and supermarkets are cheaper and have a wide choice. Off-vehicle passenger care is important: drivers help passengers into the supermarket and take shopping to their homes. The service level provided by the supermarket is also important, demonstrating the need to consult with destination organisations. This study also consulted supermarket staff, Nexus, the sheltered housing and the operator in order to ascertain service improvements and how to move it from a pilot to a permanent service. The success of a targeted service to shops suggests that the concept can be extended to other destinations based upon stakeholder consultation [10].

In both studies people reported that whilst many buses and taxis are classed as accessible, an accessible vehicle for one person is not accessible for another, particularly with taxis. The TaxiLink contract had a limited number of vehicles, and passengers could not specify vehicle type when booking a journey, whereas TaxiCard enables access to a range of operators and vehicles; the Shopping Pilot vehicle is satisfactory to all except those with personal electric scooters. With regard to conventional services, there is a lack of consistency in vehicle provision during the day on some routes, again restricting travel options $[10,11]$.

The ineligibility of concessionary fares on non-registered services is not necessarily a barrier: both studies found that older people are prepared to pay for services if they meet their requirements, such as being door-to-door, at appropriate journey times and are easy to book $[10,11]$.

Partly in response to these studies Nexus developed a package of options that are suited to older people. The prime objective is to enable as many people as possible to use conventional public transport, since this has a wide network at the least cost to Nexus - many services are commercially operated and conventional services cost less to support than flexible services. This approach was justified as vehicle design has improved to allow easy access (kneeling and low floor) boarding. About $80 \%$ of buses operating in Tyne and Wear are wheelchair accessible and it is estimated that all will be accessible within two years. Near to conventional hail-and-ride has been introduced on peri-urban estates using registered taxibuses. The barrier to accessing conventional public transport can be lowered by introducing supporting measures. For example, Nexus now offers the Companion Card which enables people entitled to use TaxiCard and concessionary travel to have a free of charge companion to offer support on registered services. In partnership with bus operators and the local authorities, Nexus has also introduced the Bridge Card. Holders can inform transport operating staff discretely that they may need additional time or support whilst travelling due to age, disability, illness, or lack confidence (this last criteria being relevant to older people who have not used public transport for many years).

This leaves a relatively small proportion of people needing non-conventional services. LinkUp is a registered flexible transport service that is available throughout Tyne and Wear: the overall service design is many-to-few, which picks up on estates and takes people to fixed routes or to key destinations, such as shopping centres. The success of the Section 19 group transport to targeted destinations is supporting expansion of this concept where the need can be established through consultation. For older people who are more mobility 
impaired the TaxiLink service is available (to be replaced by TaxiCard in autumn 2008) for people who meet stringent mobility criteria [11]. Group transport is also available to TaxiCard members with a similar destination and time.

For all supported services the local authority can introduce Quality Contracts which specify operator criteria such as the design of the vehicle and passenger care training for drivers.

This package approach intends to encourage a wide range of providers to participate and be innovative, e.g. by introducing taxibuses and developing group transport. However, the commercial providers of the core conventional services must not feel threatened by services that they do not provide, as withdrawal of non-supported services creates a gap in the network that is costly to support.

\subsection{Dissemination}

It is critical that information is disseminated to operators so that they understand the opportunities and requirements that these options present. Having established the package of services (and the operators) the potential users need to be made aware of them and understand how to use them. High profile dissemination about public transport services is seldom a priority in the UK, particularly for services that are not available for the general public and where there are fears that over-publicity will make demand exceed supply, e.g. in the Shopping Pilot [10] demand was suppressed by not actively giving information about the service to older people living near to the residential homes.

Posters and timetables at places frequented by the target users, bus stations and bus stops, and advertisements in newspapers, on the radio and television are obvious dissemination methods. The last two are seldom explored: however, radio advertisements are considered worthwhile for DRT services in Co. Kilkenny, Ireland [12]. Conversely, Italian local authorities are usually pro-active in dissemination and the impact of poor publicity was noted for a new DRT service in Carrara [12]. As noted earlier, the more flexible the service, the less visible it is to users, making active dissemination critical for success [13]. Criticism of dissemination materials was a finding of the TaxiLink study [11].

A highly effective method is to inform the organisations that represent older people as they can interpret the information for potential users. Organisations are usually informed on an individual basis, but it could be more beneficial to arrange workshops at regular intervals, e.g. twice a year, so they can also provide feedback about services and shared experiences of services can be recorded and used to implement improvements. The importance of word of mouth between users (as well as from their representatives) cannot be underestimated.

Although local authorities do not support car share and car clubs (except for employees) it would be advantageous for local authorities to add them to the transport package for older people. Car clubs and car share are largely organised through the internet, therefore dissemination presents a particular barrier to older people despite a rapid increasing number of 'silver surfers.' In 2006, 84\% of 1624 year olds had used the internet within the last three months, compared with $52 \%$ of people aged 55-64 and $15 \%$ of those aged 65 and over [14]. 
The content of dissemination materials is important, particularly for unconventional services that do not have a fixed timetable and need to be prebooked. Evidence suggests that the most important factors for individuals about a new service are the cost, the destination, the timetable, a telephone number for information, the operator and general accessibility of the bus [10] together with presentation characteristics such as sans serif font and at least pitch size 12 [11].

\section{Conclusions}

The success of any transport service depends upon passenger acceptance. Not only do passengers need to be consulted as to what they consider appropriate, but also other key stakeholders require consultation. This paper demonstrates that a package of services will give the end user more choice and also enable a range of service providers to contribute to the urban public transport network. For all stakeholders, clear dissemination of new concepts is critical to the success of public transport services, particularly for unconventional options. This range of options available in the UK could be considered by other EU states. Conversely, the nature of the deregulated and fragmented UK public transport market may be detrimental to the most efficient delivery of transport services to older people.

\section{References}

[1] http://www.statistics.gov.uk/cci/nugget.asp?ID=949 .

[2] Church, A., Frost, M. and Sullivan, K., Transport and social inclusion in London. Transport Policy, 7, pp. 195-205, 2000.

[3] http://www.politics.co.uk/news/public-services/road/congestioncharge/bus-deregulation-isnt-working-\$455887.htm .

[4] Brake, J.F., Mulley, C. and Nelson, J.D., Good Practice Guide for Demand Responsive Transport Services using Telematics. Contract Report. University of Newcastle upon Tyne, 2006.

[5] http://www.transportoffice.gov.uk/crt/busandcoachoperators/busandcoacho perators.htm.

[6] http://www.dft.gov.uk/pgr/regional/buses/concessionary/nbcfaddtngrants/.

[7] http://www.transportoffice.gov.uk/crt/taxiproviders/taxiproviders.htm.

[8] http://www.accessiongis.com/ .

[9] http://www.within-reach.org.uk/index.asp.

[10] Brake, J.F., Evaluation of Older People's Community Transport Shopping Pilot. Contract Report for Nexus, 2007.

[11] Brake, J.F., Provision of Transport for Disabled and Elderly People: TaxiCard - TaxiLink Preference Survey. Contract Report for Nexus, 2007.

[12] Brake, J.F., et al, Results Cross Site Evaluation. SUNRISE Interreg IIIC Project, 2004-03-2S0001I. Contract Report 5. CEC, Bruxelles, 2006.

[13] Brake, J.F., Mulley, C., Nelson, J.D. and Wright, S., Key lessons from recent experience with Flexible Transport Services. Transport Policy, 2007.

[14] http://www.statistics.gov.uk/CCI/nugget.asp?ID=1711\&Pos=2\&ColRank= $1 \&$ Rank $=192$. 